\title{
ECLETICA
}

www.scielo.br/eq

Volume 31, número 3, 2006

\section{Analysis of the structure and vibrational spectra of glucose and fructose}

\author{
Medhat Ibrahim ', Moussa Alaam ${ }^{1}$,Hanan El-Haes ${ }^{2}$, Abraham F. Jalbout ${ }^{3}$, Aned de Leon ${ }^{4}$ \\ ${ }^{\prime}$ Spectroscopy Department, National Research Center, NRC., Dokki, Cairo, Egypt. \\ ${ }^{2}$ Faculty of Women for Arts, Science, and Education, Ain Shams University, Cairo, Egypt. \\ ${ }^{3}$ Institute of Chemistry, National Autonomous University of Mexico, Mexico City, Mexico \\ ${ }^{4}$ NASA Astrobiology Institute (NAI), Department of Chemistry and Steward Observatory, \\ The University of Arizona, Tucson, AZ 85721 USA
}

\begin{abstract}
Molecular modelling using semiempirical methods AM1, PM3, PM5 and, MINDO as well as the Density Functional Theory method BLYP/DZVP respectively were used to calculate the structure and vibrational spectra of d-glucose and d-fructose in their open chain, $\alpha$-anomer and $\beta$-anomer monohydrate forms. The calculated data show that both molecules are not linear; ground state and the number for the point-group $C$ is equal to 1 . Generally, the results indicate that there are similarities in bond lengths and vibrational modes of both molecules. It is concluded that DFT could be used to study both the structural and vibrational spectra of glucose and fructose.
\end{abstract}

Keywords: FTIR; D-glucose; D-fructose; $\alpha$-anomer; $\alpha$-anomer; semiempirical calculations; density functional theory (DFT).

\section{Introduction}

Carbohydrates represent a very important class of compounds in biological systems and play a key role in many processes important to life[1-3]. Hydration of carbohydrates is an important point of research[4-5]. Spectroscopic parameters can be well determined using molecular modelling calculations. Molecular Mechanics (MM) can model very large compounds quickly[6]. Both Quantum Mechanics (QM) and (MM) are mixed to calculate several parameters for biological and many other systems[7-11]. The crystalline structures of $\alpha-\mathrm{D}$ Glucose, $\alpha$-D-Glucose monohydrate and $\beta$-DGlucose were studied by means of ab initio calculations[12]. The interaction between water and $\alpha / \beta$-D-Glucose was studied by Density Functional Theory (DFT) B3LYP level[13]. Both $\alpha$ and $\beta$-D-
Glucose anomers were studied in gas phase and solution form using both DFT and ab initio calculations [14]. In the same way, molecular dynamics (MD) study of 1,5 anhydro-D-Fructose in aqueous solution have been carried out[15]. High-level DFT methods were used to study the conformational preferences of the ${ }^{4} \mathrm{C}_{1}$ and ${ }^{1} \mathrm{C}_{4}$ chair conformations as well as boat and skew-boat conformations of $\alpha$ - and $\beta$-D-Mannopyranose[16]. Generally vibrational spectroscopic method of analyses were found useful to characterize carbohydrates. The Raman optical activity of D-fructose in aqueous solution were reported[17]. Both physicochemical properties and vibrational spectra of small carbohydrates was studied to asses the role of water in sweet-taste of carbohydrate. So that, D-Fructose in water and alkali solutions were studied using Raman spectroscopy in the $\mathrm{OH}$ 
stretching region[18]. Sequential injection Fourier Transform Infrared (FTIR) spectroscopy is presented as a fully automated method for the rapid determination of Glucose, Fructose, and Sucrose in soft drinks[19]. FTIR was also used to study the adsorption of Glucose monomer on hematite and quartz. The common adsorption mechanism indicated is a surface reaction involving the iron ion[20]. Glucose among other carbohydrate molecules were linked to maleic anhydride functionalized polystyrene by polymer analogous reactions to produce biodegradable polymers. FTIR spectra confirmed the degradation of the polymer[21].

On the basis of the above considerations, the present study aims to use molecular modelling together with the experimental measurements to study the structure and vibrational spectra of two important biological molecules, Glucose and Fructose in their open chain, $\alpha$-anomer and $\beta$ anomer monohydrate structures. Molecular modeling calculations were conducted using Semiempirical methods, AM1, PM3, PM5 and MINDO. Furthermore, the DFT (BLYP/DZVP) was also used. The structure and vibrational spectra of the two molecules were calculated. The computed BLYP/DZVP frequencies were compared with those obtained experimentally by FTIR Spectroscopy

\section{Experimental}

$\alpha$-D-Glucose and $\beta$-D-Fructose were purchased from Aldrich (molecular weight for each is 180.16) and were used without further purification. The FTIR spectra were collected for these samples using Fourier Transform IR spectrometer Nexus 670, Nicolet, USA. The number of scans was 32 and the resolution was $4 \mathrm{~cm}^{-1}$. All spectra were collected in the range (4000-400 $\mathrm{cm}^{-1}$ ). The $\mathrm{KBr}$ technique was used to prepare the samples for IR measurements.

\section{Calculation details}

Calculations were carried out on a personal computer using quantum mechanical methods as implemented with the MOPAC 2002 Version 1.33
CAChe Program (by Fujitsu). The geometry of Glucose and Fructose in their open chain, $\alpha$ anomer as well as $\beta$-anomer monohydrate structures were optimized at Semiempirical methods AM1[22], PM3[22], PM5[23] and MINDO[24] as well as DFT method, Beck-Lee-Yang-Parr correlation functional, BLYP with the double zeta, DZVP basis set. For the DFT method, the vibrational spectra were performed after the harmonic approximation.

\section{Results and Discussion}

Optimized geometry: The calculations of geometry optimization locate the lowest energy molecular structure in close proximity to the specified starting structure[25-27]. The symmetry of the molecular structures as shown in Figure 1 corresponds to the $C_{1}$ point group. The two studied molecules reveal that they both have the same chemical formula, which is $\mathrm{C}_{6} \mathrm{H}_{12} \mathrm{O}_{6}$. The open chain D-Glucose molecule in Figure 1-a starts with a $\mathrm{CHO}$ group bonded to four subsequent carbon atoms and each carbon atom carries a hydroxyl group and a hydrogen atom and the last carbon atom is bonded to methyl group $\mathrm{CH}_{2} \mathrm{OH}$. Similarly the open chain DFructose can be described as in Figure 1-d. In contrast to D-Glucose the structure of the optimized D-Fructose contains 4 carbon atoms between two methyl groups $\mathrm{CH}_{2} \mathrm{OH}$. The second carbon atom is bonded to an oxygen atom to form $\mathrm{C}=\mathrm{O}$ while the rest of carbon atoms is carrying hydrogen atoms and hydroxyl groups. The flexibility of these open chain molecules together with the high reactivity of the $\mathrm{CH}_{2} \mathrm{OH}$ and $\mathrm{CHO}$ groups lead to an internal cyclizations, as the carbonyl groups reacts with one of the hydroxyl groups from the other end of the molecule. As shown in Figure 1-b, the resulting ring contains 5 carbon atoms and one oxygen atom. The closure of the linear molecules to make a ring creates a new chiral center at $\mathrm{C}_{1}$, called the anomeric carbon. When the hydroxyl group is attached to $\mathrm{C}_{1}$, the carbon atom next to the ring oxygen and which does not carry the methyl group is in an axial or equatorial position with respect to the ring, these anomers are called $\alpha$ and $\beta$ 
anomers[12]. The bond distances C-C, C-H, O$\mathrm{H}, \mathrm{C}-\mathrm{O}$ and $\mathrm{C}=\mathrm{O}$ were calculated and presented in Tables 1 to 3. Regarding AM1, PM3, PM5 and MINDO results, there is a small variation in the calculated bond lengths as compared to BLYP/DZVP.
As can be seen in Table 3 the two molecules show comparable bond distances at the BLYP level of theory. The calculated bond lengths for D-Glucose are $1.537 \AA, 1.120 \AA$, $0.984 \AA, 1.455 \AA$ and $1.235 \AA$ for the bonds $\mathrm{C}-\mathrm{C}$ of $\mathrm{CH}_{2} \mathrm{O}, \mathrm{C}-\mathrm{H}, \mathrm{O}-\mathrm{H}, \mathrm{C}-\mathrm{O}$ and $\mathrm{C}=\mathrm{O}$ respectively.

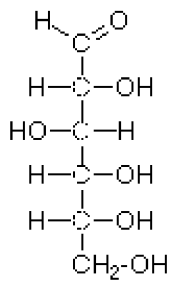

a-

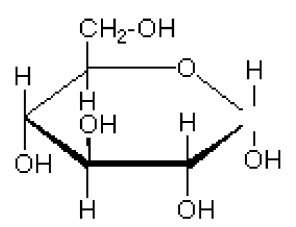

b-

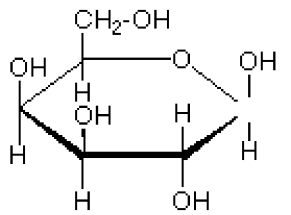

c-<smiles>O=C(CO)C(O)C(O)C(O)CO</smiles>

d-

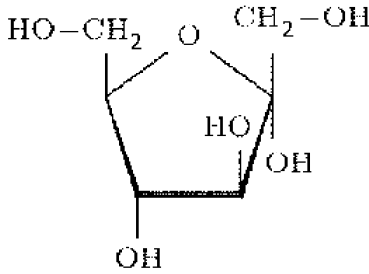

e-

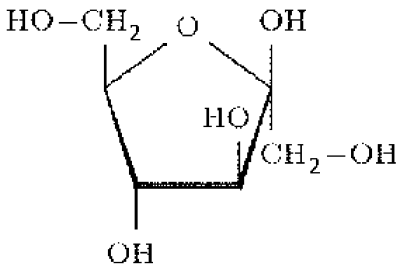

f-

Figure 1. Structure of a- D-Glucose, b- $\alpha$-D-Glucose, $c-\beta$-D-Glucose, d- D- Fructose, e- $\alpha$-DFructose and f- $\beta$-D- Fructose.

Table 1. Calculated bond lengths in angstroms for D-Glucose and $\alpha$-D- Glucose, which were optimized at the semiempirical AM1, PM3, PM5, MINDO as well as Density Functional method BLYP/DZVP levels of theory.

\begin{tabular}{lcccccccccc}
\hline \multirow{2}{*}{ Bond } & \multicolumn{2}{c}{ AM1 } & \multicolumn{2}{c}{ PM3 } & \multicolumn{2}{c}{ PM5 } & \multicolumn{2}{c}{ MINDO } & \multicolumn{2}{c}{ BLYP } \\
\cline { 2 - 11 } Distance & $\mathrm{D}$ & $\alpha-\mathrm{D}$ & $\mathrm{D}$ & $\alpha-\mathrm{D}$ & $\mathrm{D}$ & $\alpha-\mathrm{D}$ & $\mathrm{D}$ & $\alpha-\mathrm{D}$ & $\mathrm{D}$ & $\alpha-\mathrm{D}$ \\
$\mathrm{C}-\mathrm{C}\left(\mathrm{CH}_{2} \mathrm{O}\right)$ & 1.513 & 1532 & 1.531 & 1.544 & 1.539 & 1.559 & 1.554 & 1.577 & 1.537 & 1.532 \\
$\mathrm{C}-\mathrm{C}$ (Ring) & & 1.534 & & 1.548 & & 1.544 & & 1.582 & & 1.559 \\
$\mathrm{C}-\mathrm{H}$ & 1.132 & 1.123 & 1.117 & 1.104 & 1.129 & 1.104 & 1.124 & 1.121 & 1.120 & 1.108 \\
$\mathrm{O}-\mathrm{H}$ & 0.968 & 0.964 & 0.959 & 0.949 & 0.955 & 0.949 & 0.947 & 0.947 & 0.984 & 0.980 \\
$\mathrm{C}-\mathrm{O}$ & 1.415 & 1.419 & 1.405 & 1.400 & 1.389 & 1.400 & 1.398 & 1.394 & 1.454 & 1.447 \\
$\mathrm{C}=\mathrm{O}$ & 1.231 & & 1.213 & & 1.209 & & 1.221 & & 1.235 & \\
\hline
\end{tabular}

D: Open chain D-Glucose, $\alpha$-D: $\alpha$-anomer Glucose 
Table 2. Calculated bond lengths in angstroms for D-Fructose and $\alpha$-D-Fructose, which optimized at the semiempirical AM1, PM3, PM5, MINDO as well as Density Functional method BLYP/DZVP levels of theory.

\begin{tabular}{lcccccccccc}
\hline \multirow{2}{*}{ Bond } & \multicolumn{2}{c}{ AM1 } & \multicolumn{2}{c}{ PM3 } & \multicolumn{2}{c}{ PM5 } & \multicolumn{2}{c}{ MINDO } & \multicolumn{2}{c}{ BLYP } \\
\cline { 2 - 11 } Distance & $\mathrm{D}$ & $\alpha-\mathrm{D}$ & $\mathrm{D}$ & $\alpha-\mathrm{D}$ & $\mathrm{D}$ & $\alpha-\mathrm{D}$ & $\mathrm{D}$ & $\alpha-\mathrm{D}$ & $\mathrm{D}$ & $\alpha-\mathrm{D}$ \\
$\mathrm{C}-\mathrm{C}\left(\mathrm{CH}_{2} \mathrm{O}\right)$ & 1.505 & 1.546 & 1.523 & 1.566 & 1.524 & 1.582 & 1.550 & 1.600 & 1.529 & 1.565 \\
$\mathrm{C}-\mathrm{C}(\mathrm{Ring})$ & & 1.536 & & 1.570 & & 1.587 & & 1.610 & & 1.562 \\
$\mathrm{C}-\mathrm{H}$ & 1.123 & 1.122 & 1.105 & 1.108 & 1.120 & 1.119 & 1.120 & 1.123 & 1.110 & 1.106 \\
$\mathrm{O}-\mathrm{H}$ & 0.967 & 0.964 & 0.950 & 0.948 & 0.955 & 0.953 & 0.947 & 0.947 & 0.987 & 0.980 \\
$\mathrm{C}-\mathrm{O}$ & 1.410 & 1.416 & 1.398 & 1.405 & 1.389 & 1.393 & 1.390 & 1.392 & 1.428 & 1.452 \\
$\mathrm{C}=\mathrm{O}$ & 1.236 & & 1.216 & & 1.214 & & 1.223 & & 1.243 & \\
\hline
\end{tabular}

D: Open chain D-Fructose, $\alpha$-D: $\alpha$-anomer Glucose

Table 3. Comparison between bond lengths in angstroms for Glucose and Fructose which re calculated at the Density Functional Theory BLYP/DZVP level of theory.

\begin{tabular}{lcccccc}
\hline Bond Distance & \multicolumn{3}{c}{ Glucose } & \multicolumn{3}{c}{ Fructose } \\
\hline & $\mathrm{D}$ & $\alpha-\mathrm{D}$ & $\beta-\mathrm{D} \mathrm{M}$ & $\mathrm{D}$ & $\alpha-\mathrm{D}$ & $\beta-\mathrm{D} \mathrm{M}$ \\
$\mathrm{C}-\mathrm{C}\left(\mathrm{CH}_{2} \mathrm{O}\right)$ & 1.537 & 1.532 & 1.535 & 1.529 & 1.565 & 1.559 \\
$\mathrm{C}-\mathrm{C}(\mathrm{Ring})$ & & 1.559 & 1.559 & & 1.562 & 1.560 \\
$\mathrm{C}-\mathrm{H}$ & 1.120 & 1.108 & 1.113 & 1.110 & 1.106 & 1.105 \\
$\mathrm{O}-\mathrm{H}$ & 0.984 & 0.980 & 0.980 & 0.987 & 0.980 & 0.978 \\
$\mathrm{C}-\mathrm{O}$ & 1.454 & 1.447 & 1.450 & 1.428 & 1.452 & 1.449 \\
$\mathrm{C}=\mathrm{O}$ & 1.235 & & & 1.243 & & \\
\hline
\end{tabular}

D: Open chain, $\alpha$-D: $\alpha$ - anomer and $\beta$-DM: $\beta$-anomer monohydrate

Similarly the calculated distances for the same bonds for D-Fructose are $1.529 \AA$, $1.110 \AA, 0.987$ $\AA$, $1.428 \AA$ and $1.243 \AA$, respectively. Comparing between D-Glucose and D-Fructose structures one can observe a similarity in the calculated bond distances. As shown in Table 3 a slight change in the structure is noticed as a result of changing open chain into anomeric. Momany[13] studied the effect of hydration on the $\alpha$-D Glucopyrnose. It is stated that, although monohydrated $\beta$-D Glucopyranose has only onewater molecule good geometries are obtained for this structure. It is proposed that, both of $\alpha$ and $\beta$ anomers can be studied in its monohydrate form. At this level of theory $\alpha$-anomer monohydrate is unstable and no optimal structure is found. On the other hand, the optimum structure of $\beta$-anomer monohydrate has been found. As seen in Table 3, it is clear that solution phase is slightly lower than gas phase. It seems to be that the molecules in gas phase are rearranged so that their bonds are enlarged slightly as compared with monohydrate structure.

Infrared spectra: Assignments of infrared frequencies are achieved by comparing of the band positions and intensities observed in IR spectra with wavenumbers and intensities from molecular modeling calculations. As seen in Table 4 there are similarities in vibrational spectra of both D-glucose and D-Fructose. The spectra can be assigned generally as in the following: The $\mathrm{OH}$ vibrational stretching is calculated to be in the region 3876 to $3005 \mathrm{~cm}^{-1}$, then the $\mathrm{CH}$ vibrations up to $2061 \mathrm{~cm}^{-1}$. The 
$\mathrm{C}=\mathrm{O}$ stretching is calculated from 1849 to 1634 $\mathrm{cm}^{-1}$. A combination band of $\mathrm{OCH}$ and $\mathrm{COH}$ deformation is calculated from 1526 to $1347 \mathrm{~cm}^{-1}$. Then the in plane $\mathrm{CH}$ and $\mathrm{OH}$ deformation from 1362 to $1191 \mathrm{~cm}^{-1}$ can be observed. A band of $\mathrm{CO}$ and CC stretching is regarded from 1191 to $995 \mathrm{~cm}^{-1}$. The following spectra are assigned as

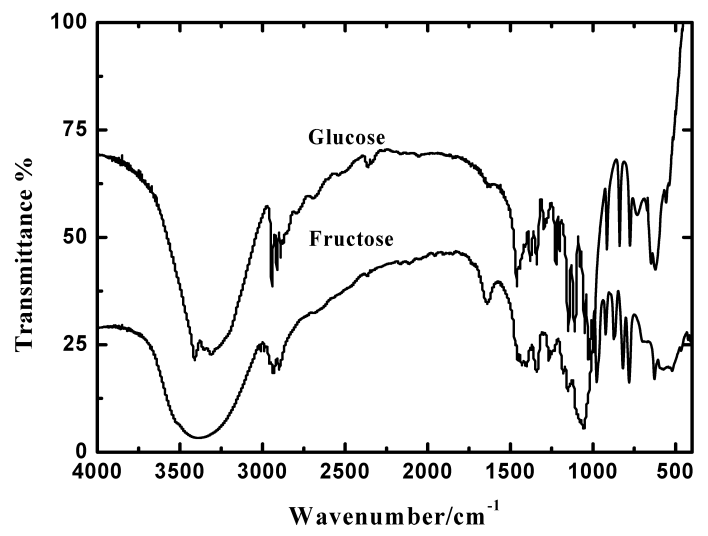

Figure 2. FTIR absorption spectra of both $\alpha$-DGlucose and $\beta$-D-Fructose.
$\mathrm{CH}$ deformation followed by $\mathrm{CH} 2$ vibration. As a general trend, Semiempirical methods AM1, PM3, PM5 and MINDO gave higher calculated frequencies as compared to scaled DFT method. This can be attributed to the effect of electron correlation, which is not included in semiempirical calculations.

To compare the calculated spectra with the experimental ones, FTIR Spectroscopy can be used to study the two molecules. Figure 2 shows the FTIR spectra of $\alpha$-D-Glucose and $\beta$ D-Fructose respectively. Table 5 shows the assignment of the main characteristic absorption bands for each of two molecules. The vibrational spectra that indicated in both Figure 2 and Table 5 can be classified into two main groups of spectra. The region from 600 to $1500 \mathrm{~cm}^{-1}$ in which $\mathrm{C}-\mathrm{O}$ and $\mathrm{C}-\mathrm{C}$ groups vibration modes are present and the carbohydrates generally shows their characteristic bands. On the other hand the bands from 2900 to $3450 \mathrm{~cm}^{-1}$ assigned to $\mathrm{CH}$ and $\mathrm{OH}$ vibrations groups. $\alpha$-D-anomer is tested with one water molecule (monohydrate form) and compared with both $\beta$-anomer as well as

Table 4. Calculated Infrared frequencies in $\mathrm{cm}^{-1}$ of the main characteristic absorption bands of open chain D-Glucose and D-Fructose.

\begin{tabular}{llllllllll}
\hline \multicolumn{2}{c}{ AM1 } & \multicolumn{2}{c}{ PM3 } & \multicolumn{2}{c}{ PM5 } & \multicolumn{2}{c}{ MINDO } & \multicolumn{2}{c}{ BLYP/DZVP } \\
\hline D-G & D-F & D-G & D-F & D-G & D-F & D-G & D-F & D-G & D-F \\
3482 & 3500 & 3869 & 3876 & - & 3143 & 3994 & 3994 & 3453 & 3463 \\
3460 & 3458 & 3768 & 3830 & - & 3118 & 3988 & 3252 & 3443 & 3005 \\
3443 & 3020 & 3022 & 3020 & 3132 & 3043 & 3271 & 3185 & 2969 & 2953 \\
2061 & 2059 & 1965 & 1973 & 1849 & 1841 & 2122 & 2127 & 1656 & 1634 \\
1571 & 1577 & 1525 & 1460 & - & 1358 & 1526 & 1569 & 1456 & 1613 \\
1430 & 1513 & 1408 & 1428 & - & 1352 & 1426 & 1537 & 1366 & 1392 \\
1404 & 1444 & 1398 & 1406 & 1366 & 1337 & 1396 & 1441 & 1347 & 1320 \\
1372 & 1322 & 1362 & 1307 & 1319 & 1332 & 1304 & 1354 & 1231 & 1276 \\
1257 & 1300 & 1262 & 1268 & 1256 & 1254 & 1260 & 1292 & 1153 & 1148 \\
1207 & 1279 & 1225 & 1244 & 1217 & 1222 & 1170 & 1214 & 1148 & 1093 \\
1191 & 1161 & 1172 & 1227 & 1160 & 1149 & 1132 & 1140 & 1069 & 1001 \\
1123 & 1066 & 1111 & 1159 & 1095 & 1076 & 1084 & 1092 & 1036 & 953 \\
1060 & 1015 & 1016 & 1085 & 1000 & 1019 & 1017 & 1018 & 954 & 856 \\
963 & 974 & 947 & 911 & 946 & 951 & 953 & 978 & 842 & 816 \\
926 & 957 & 897 & 884 & 887 & 890 & 798 & 965 & 770 & 784 \\
797 & 793 & 740 & 753 & 751 & 746 & 760 & 768 & 625 & 651 \\
\hline
\end{tabular}

D-G: Open chain D-Glucose and D-F:Open chain D-Fructose. 
Table 5. Comparisons between both experimental and BLYP calculated Infrared frequencies in $\mathrm{cm}^{-1}$ for both $\alpha$-D-Glucose and $\beta$-D-Fructose as well as $\alpha$ - D-Glucose and $\beta$-D-Fructose monohydrates.

\begin{tabular}{|c|c|c|c|c|c|c|c|}
\hline & \multicolumn{3}{|c|}{ D-Glucose } & \multicolumn{4}{|c|}{ D-Fructose } \\
\hline IR & $\alpha-\mathrm{D}$ & $\beta-\mathrm{D}-\mathrm{M}$ & Assignment & IR & $\alpha-\mathrm{D}$ & $\beta$-D-M & Assignment \\
\hline 3410 & 3418 & 3146 & $v \mathrm{OH}$ & 3393 & 3428 & 3513 & $v \mathrm{OH}$ \\
\hline 3393 & 3408 & 3123 & $v \mathrm{OH}$ & 2933 & 2975 & 2957 & $v_{\mathrm{s}} \mathrm{CH}$ of $\mathrm{C} 2$ \\
\hline 2944 & 2963 & 3099 & $v_{\mathrm{s}} \mathrm{CH}$ of $\mathrm{C} 2$ & 2899 & 2923 & 2925 & $v_{\text {as }} \mathrm{CH}$ of $\mathrm{Cl}$ \\
\hline 2913 & 2939 & 3085 & $v_{\mathrm{as}} \mathrm{CH}$ of $\mathrm{C} 1$ & & & & \\
\hline 1460 & 1441 & 1465 & $\begin{array}{c}\delta \mathrm{CH}_{2}+\delta \mathrm{OCH}+ \\
\delta \mathrm{CCH}\end{array}$ & 1637 & 1634 & 1665 & $\delta \mathrm{OH}$ \\
\hline 1382 & 1352 & 1390 & $\begin{array}{c}\delta \mathrm{OCH}+\delta \mathrm{COH}+ \\
\delta \mathrm{CCH}\end{array}$ & 1402 & 1392 & 1417 & $\begin{array}{c}\delta \mathrm{OCH}+\delta \mathrm{COH}+ \\
\delta \mathrm{CCH}\end{array}$ \\
\hline 1340 & 1333 & 1320 & $\delta \mathrm{CCH}+\delta \mathrm{OCH}$ & 1340 & 1320 & 1338 & $\Delta \mathrm{CCH}+\delta \mathrm{OCH}$ \\
\hline 1224 & 1218 & 1278 & $\begin{array}{c}\delta \mathrm{CH}+\delta \mathrm{OH} \text { in } \\
\text { plane }\end{array}$ & 1265 & 1276 & 1292 & $\begin{array}{c}\delta \mathrm{OH} \text { in plane, } \delta \\
\mathrm{CCO}\end{array}$ \\
\hline 1203 & 1220 & 1232 & $\begin{array}{c}\delta \mathrm{CH}+\delta \mathrm{OH} \text { in } \\
\text { plane }\end{array}$ & & & & \\
\hline 1149 & 1137 & 1205 & $v \mathrm{CO}+v \mathrm{CC}$ & 1149 & 1148 & 1166 & $\begin{array}{c}v \mathrm{CO}+v \mathrm{CC}+\delta \\
\mathrm{CCC}\end{array}$ \\
\hline 1111 & 1116 & 1162 & $v \mathrm{CO}$ & 1057 & 1082 & 1059 & $v \mathrm{CO}$ \\
\hline 1050 & 1058 & 1088 & $v \mathrm{CO}+v \mathrm{CC}$ & 977 & 990 & 990 & $v \mathrm{CO}+\delta \mathrm{CCO}$ \\
\hline 1025 & 1026 & 1066 & $v \mathrm{CO}$ & 923 & 943 & 951 & $\begin{array}{l}v \mathrm{CO}+v \mathrm{CCH}+v_{\mathrm{as}} \\
\text { ring of pyranose }\end{array}$ \\
\hline 995 & 944 & 1032 & $v \mathrm{CO}+v \mathrm{CC}$ & 873 & 856 & 908 & $\begin{array}{c}\delta \mathrm{CH}+v \mathrm{CC}+ \\
\delta \mathrm{CCH}\end{array}$ \\
\hline 915 & 900 & 993 & $\begin{array}{l}v \mathrm{CO}+v \mathrm{CCH}+v_{\mathrm{as}} \\
\text { ring of pyranose }\end{array}$ & 818 & 816 & 884 & $\delta \mathrm{CH}$ \\
\hline 837 & 834 & 909 & $\delta \mathrm{CH}$ & 780 & 784 & 828 & $\delta \mathrm{CCO}+\delta \mathrm{CCH}$ \\
\hline 776 & 762 & 815 & $\delta \mathrm{CCO}+\delta \mathrm{CCH}$ & 627 & 644 & 658 & $\mathrm{CH}_{2}+\mathrm{CH}$ \\
\hline 622 & 619 & 694 & $\mathrm{CH}_{2}$ & & & & \\
\hline
\end{tabular}

FTIR: Experimental frequencies, $\alpha$-D: $\alpha$-D-anomer, $\beta$-DM: $\beta$-D-anomer monohydrate.

experimental FTIR frequencies for $\alpha$-D-anomer. It is worth to mention that, the $\beta$-D-anomer assignment is in a good agreement with that presented by Guo and Zhang[28]. Regarding the results of $\alpha$-D-anomer, it is clear that the computed frequencies are in a good agreement with experimental ones except for $\mathrm{CH}$ and $\mathrm{OH}$ region. But there is agreement in the characteristic region of carbohydrate. In this region, there is a good correlation between both $\alpha$ and $\beta$ anomer in one hand and the experimental frequencies on the other. The computed frequencies of $\alpha$-anomer for both Glucose and Fructose are in a good agreement with experimental frequencies for both carbohydrate region as well as $\mathrm{OH}$ and $\mathrm{CH}$ region. Comparing computed and the experimental frequencies one can conclude that, accurate results could be achieved with scaled DFT method BLYP/DZVP with higher computation time as compared to semiempirical methods.

\section{Conclusions}

In the present study molecular models for two biological molecules, Glucose and Fructose are presented on the basis of Semiempirical and DFT calculations. The models present the structure and vibrational spectra for D-Glucose and D- 
Fructose in their open chain, $\alpha$-anomer and $\beta$ anomer monohydrate forms. The obtained result indicates that there are similarities in the structural and vibrational characteristic of both molecules. Although monohydrate $\alpha$-anomer is not a complete hydration structure, its computed IR spectra is in a good agreement with experimental spectra for $\beta$-D-Fructose. In addition, the computed spectra for $\alpha$-D-Glucose monohydrate are in a good agreement with experimental one in the characteristic region $\left(600-1500 \mathrm{~cm}^{-1}\right)$ and far from it in the $\mathrm{OH}$ region. It can be concluded that with a comparable results and lower computation time, semiempirical method could be used to study carbohydrates such as Glucose and Fructose. On the other hand for accurate and precise structural and vibrational data DFT method could be used with a good agreement with experimental results.

\section{Received 27 July 2006 \\ Accepted 17 August 2006}

\section{References}

[1] R. A. Dwek, Chem. Rev. 96 (1996) 683-720.

[2] R. W. Binkley, Modern carbohydrate chemistry, M. Dekker Inc., New York., 1988.

[3] Z. Gyöwrgydeak and I. Pelyvas, Monoscaccharide sugars, Academic press, New York, 1998.

[4] J. Madox, Nature 364 (1993) 669-703.

[5] Galema, S. A. Blandamera, M. J. and Engberts, J. B. F. N., J. Org. Chem. 57 (1992) 1995-2001.

[6] A. R. Leach, Molecular Modelling Principles and Applications, Longman, Essex. 1996.
[7] N. Reuter, A. Dejaegere, B. Maigret and M. Karplus, J. Phys. Chem.A. 104 (2000) 1720-1735.

[8] J. Gao, Acc. Chem. Res. 29 (1996) 298-305.

[9] M. A. Cunningham, L. L. Ho, D. T. Nguyen, R. E. Gillilan and P. A. Bash, Biochemistry, , M. A. 36 (1997) 4800-4816.

[10] M. S. Cheung, I. Daizadeh, A. A. Stuchebrukhov and P. F. Heelis, Biophys. J. 76 (1999) 1241-1249.

[11] K. P. Eurenius, D. C. Chatfield, B. R. Brooks and M. Hodoscek, Intern. J. Quant. Chem. 60 (1996) 1189-1200.

[12] C. Molteni and M. Parrinello, Cem. Phys. Lett. 275 (1997) 409-413.

[13] F. A. Momany, M. Appell, G. Strati and J. L. Willett, Carbohydrate Research 339 (2004) 553-567.

[15] C. Arujo-Andrade, F. Ruiz, J. R. Martinez-Mendoza and H. Terrones, J. Mol. Struct. THEOCHEM. 714 (2005) 143146.

[16] J. Behler, D. W. Price and M. G. B. Drew, Phys. Cehm. Chem. Phys. 3 (2001) 588-601.

[17] A. Michael, J. L. Willett and F. A. Momany, Carbohydrate Research 340 (2005) 459-468.

[18] F. B. Alasdair, H. Lutz and D. B. Laurence, Spectrochimica Acta A. 51 (1995) 1367-1378.

[19] M. Mathlouthi, F. Hutteau and J. F. Angibous, Food Chemistry 56 (1996) 215-221.

[20] L. Hai and L. Bernhard, Analytica Chimica Acta 422 (2000) 63-69.

[21] S. Pavlovic and P. R. G. Brandao, Minerals Engineering 16 (2003) 1117-1122.

[22] P. Galgali, U. S. Puntambekar, D. V. Gokhale and A. J. Varma, Carbohydrate Polymers 55 (2004) 393-399.

[23] M. J. S. Dewar, E. G. Zoebisch, E. F. Healy and J. J. P. Stewart, J. Am. Chem. Soc. 107 (1985) 3902-3909.

[24] J. J. P. Stewart, J. Comp. Chem. 10 (1989) 209-220.

[25] J. S. D. Michael and T. Walter, J. Am. Chem. Soc. 99 (1977) 4899-4907.

[26] J. B. Foresman and A. Frisch, Exploring chemistry with electronic structure methods, 2nd ed., Gaussian Inc., 1996.

[27] A. Komornicki and G. Fitzgerald, J. Chem. Phys. 98 (1993) 1398.

[28] J. Guo and X. Zhang, Carbohydrate Research 339 (2004) 1421-1426. 
